\title{
Journal of Pharma and Pharmaceutical Sciences
} \section{National Pharmacy Practice Programs at Ministry of Health in Saudi Arabia}

\author{
Yousef Ahmed Alomi Bsc. Pharm, Msc. Clin Pharm, BCPS, BCNSP, DiBA, CDE
}

General Manager of General Administration of Pharmaceutical Care, Ministry of Health, Riyadh, Saudi Arabia

\begin{abstract}
*Corresponding author: Yousef Ahmed Alomi, General Administration of Pharmaceutical Care Ministry of Health, P.O.BOX 100, Riyadh 11392, Riyadh, Saudi Arabia; Tel: +966504417712; Email: yalomi@gmail.com
\end{abstract}

Article Type: Editorial, Submission Date: 18 September 2015, Accepted Date: 1 October 2015, Published Date: 14 October 2015.

Citation: Yousef Ahmed Alomi (2015) National Pharmacy Practice Programs at Ministry of Health in Saudi Arabia. J.Pharm Pharm Scien 1(2): 17-18. doi: https://doi.org/10.24218/vjpps.2015.10.

Copyright: () 2015 Yousef Ahmed Alomi. This is an open-access article distributed under the terms of the Creative Commons Attribution License, which permits unrestricted use, distribution, and reproduction in any medium, provided the original author and source are credited.

Keyword: Pharmacy Practice, Clinical Pharmacy, Pharmacist, $\mathrm{MOH}$, Saudi Arabia.

\section{Introduction}

Pharmacy Education had been started in Saudi Arabia in 1959 , and included Clinical Pharmacy in the pharmacy curriculum in 1976 at college of pharmacy in King Saud University, then changed to Doctor of Pharmacy (Pharm. D) degree as clinical pharmacy education in early 2010s [1-3]. Over more than 40 years; the colleges of pharmacy expanded to more than twenty and graduate almost more than 600 pharmacists per year with a bachelor degree of pharmacy and doctor of pharmacy $[4,5]$. Two hospital pharmacies started pharmacy practice and clinical pharmacy services; King Faisal Special Hospital and Research Center in mid-1970s [6], and King Khalid University Hospital in early 1980s [7,8], and one Hospital Pharmacy started at Ministry of Health in Riyadh region at Riyadh Central Hospital, the old name of King Saud Medical City in late 1980s, in addition to the hospital pharmacy in Dhahran. Health Center of Saudi Arabia Aramco Medical Services Organization, which is a part of the Saudi Arabian Oil Company (Saudi Aramco) $[9,10]$. In early 1990s Two Military Hospital Pharmacies at King Abdul-Aziz Medical city, and Prince Sultan Military Medical City started applying pharmacy practice and providing clinical pharmacy services. The pharmacy practice and clinical pharmacies services expanded quickly after sending several candidates to USA for studying Pharm. D and opening several colleges of pharmacies in mid-2000s. Several Studies had been published describing hospital pharmacy practice and clinical pharmacy services, however they did not differentiated between Ministry of health hospitals or Non- MOH hospitals or private hospital or even Military or National guard or university hospitals; in addition the studies described selected services without focusing on any specialized services. For instant; Intravenous admixture or inpatient pharmacy not discussed, and neither complete specialized clinical pharmacy practice programs, and did not mention any definition or how to start of clinical pharmacy program [11-13].

\section{Plan}

Ministry of Health (MOH) founded in 1951 in Saudi Arabia, with a mission stated "provision of healthcare at all levels, promotion of general health and prevention of diseases, in addition to developing the laws and legislations regulating both the governmental and private health sectors. Aside from that, $\mathrm{MOH}$ is accountable for performance monitoring in health institutions, along with the research activity and academic training in the field of health investment" [14,15]. MOH established strategic plan 2010-2020 [16,17]. This plan was implemented to cover $268 \mathrm{MOH}$ Hospital Pharmacies; more than 2250 Primary care centres Pharmacies, 136 Privates Hospital Pharmacies, and more than 7000 community pharmacies through different $\mathrm{MOH}$ general administrations, and General Administration of Pharmaceutical Care of Ministry of Health (GAPD-MOH) among them to implement pharmaceutical care $[18,19]$. GAPDMOH had mission statement "To provide the best pharmaceutical and clinical care in high quality, modern technology, and the most reasonably-priced cost for the patients of the MOH's facilities"[20]. It had strategic plan for ten years that's including Five General Strategic Goals, Provide Complete Pharmaceutical Care with Safety and Best Practice, Develop and Implement Pharmacy Human Resources, Provide Complete Pharmacy Electronic Services, Establish Innovation and Encouragement Culture at All Pharmacy sitting, and Best Utilization Resources based on Pharmacoeconomics and Health Economics Strategies. Those Goals are consisting of fifteen Initiatives, and eighty three Projects. Each project was initiated by assessment needs, key performance indicators, gap analysis, and then action plan for this project, central and peripheral committees and to be completed after five years

Currently GAPD-MOH is running more than thirty national pharmacy practices and clinical pharmacy program offers through $\mathrm{MOH}$ hospitals, primary care centers, and private hospitals adults and Pediatrics patients. Those Programs are but not limited to Antimicrobial Stewardship Program, Pain Management Program, Drug Information Services, Pharmacy Home Care Program, and Pediatric Pharmacy Programetc.

During this journey, we gained a lot of experiences, and facing lots of challenges, we could overcome it while the program is running smoothly, expanding very quickly and good achievement [21,22]. We wish to explore what had been done during the journey by writing several topics in the coming issues and but not limited to the following: 

$\checkmark$ Antimicrobial Stewardship Program
$\checkmark$ Pharmacy Infection Control
$\checkmark$ Pain Management Program
$\checkmark$ Anticoagulation Program
$\checkmark$ Drug Information Services
$\checkmark \quad$ Nutrition Support Pharmacy
$\checkmark$ Oncology Pharmacy Program
$\checkmark$ IV Therapy Program
$\checkmark$ Pharmacy Home Care Program
$\checkmark \quad$ Drug Utilization Evaluation Program
$\checkmark$ Emergency Pharmacy Program
$\checkmark$ Pharmacy Public Health Program
$\checkmark$ Mass Gathering Pharmaceutical Care
$\checkmark$ Nephrology Pharmacy Program
$\checkmark$ Pediatric Pharmacy Program

Pharmacy Practice or Clinical Pharmacy Programs are very Essential to decrease and prevent drug misadventure, improve patients outcome, and avoidable of extra and unnecessary cost in health care system.

\section{References}

1. Al-Sowaygh IA, MoradAM, Zaki MA. Clinical pharmacy education in Saudi Arabia.Journal of Clinical Pharmacy and Therapeutics.1977; 2(3): 125-129

2. Al-Sowaygh A, Morad A. M. Expanding the clinical component of pharmacy education in Saudi Arabia. Journal of Clinical Pharmacy and Therapeutics.1980; 5(3):197-202

3. Asiri YA. Emerging frontiers of pharmacy education in Saudi Arabia: The metamorphosis in the last fifty years. Saudi Pharm J.2011; 19(1): 1-8.

4. Al-Wazaify M, Matowe L, Albsoul-Younes A, Al-Omran OA. Pharmacy education in Jordan, Saudi Arabia, and Kuwait. Am J Pharm Educ. 2006; 70(1): 18

5. Moustafa MA, Towards Pharmaceutical Care Services in Saudi Arabia, Personal Experience. J Pharma Care Health Sys. 2014; 1: 4

6. Al-Jedai A. International Pharmacy Residency Accreditation: The Saudi Experience. ACCP International Clinical Pharmacist. 2011; 1(3): 1-2
7. Saddique A. Development of Clinical Pharmacy services at King Khalid University Hospital and its impact on the quality of healthcare provided. Saudi Pharm J. 2012; (20): 273-277

8. Saddique A. Poisoning in Saudi Arabia: Ten-year experience in King Khaled University Hospital. Annals of Saudi Medicine. 2001; (21): 88-91

9. Armstrong EP, Bootman JL, al-Dhewalia HM. Pharmacy practice in eastern Saudi Arabia. Am J Hosp Pharm. 1992; 49(9): 2252-4.

10. Dib JG, Abdulmohsin SA. Establishing a pharmaceutical care clinic in a Saudi Arabian health center. Am J Health-Syst Pharm. 2007; 64: 107-9

11. Alsultan MS, Khurshid F, Mayet AY, Al-Jedai AH. Hospital pharmacy practice in Saudi Arabia: Dispensing and administration in the Riyadh region.Saudi Pharm J. 2012; 20(4): 307-15.

12. Alsultan MS, Mayet AY, Khurshid F, Al-Jedai AH. Hospital pharmacy practice in Saudi Arabia: Drug monitoring and patient education in the Riyadh region. Saudi Pharm J. 2013; 21(4): 361-70.

13. Alsultan MS, Khurshid F, Salamah HJ, Mayet AY, Al-Jedai AH. Hospital pharmacy practice in Saudi Arabia: Prescribing and transcribing in the Riyadh region. Saudi Pharm J. 2012; 20(3):203-10.

14. About the Ministry - About (2015) Ministry of Health Portal, Kingdom of Saudi Arabia.Accessed 2015 Sep12.

15. About the Ministry - Mission (2015) Ministry of Health Portal, Kingdom of Saudi Arabia. Accessed 2015 Sep 12.

16. About the Ministry - Strategy (2015) Ministry of Health Portal, Kingdom of Saudi Arabia.Accessed 2015 Sep 4.

17. http://www.moh.gov.sa/Portal/WhatsNew/Documents/ OKIstragi260p.pdf.Accessed 2015 Sep 4.

18. Statistics Book - Statistical Book for Year 2013 (2015) Ministry of Health Portal, Kingdom of Saudi Arabia.Accessed 2015 Sep 16.

19. Pharmaceutical Care General Department - Director's Message (2015) Ministry of Health Portal, Kingdom of Saudi Arabia. Accessed 2015 Sep 4.

20. Pharmaceutical Care General Department-Mission (2015) Ministry of Health Portal, Kingdom of Saudi Arabia.Accessed 2015 Sep 4.

21. Pharmaceutical Care General Department - Achievements (2015) Ministry of Health Portal, Kingdom of Saudi Arabia.Accessed 2015 Sep 6.

22. http://www.moh.gov.sa/en/Documents/Facts $\% 20 \% 20$ Achievements\%20Layout-\%20final\%20-Email\%20(sQ).pdf. Accessed 2015September 6. 